\title{
Climate Change in a Multinomial World
}

\author{
Robert F. Morgan \\ Founding Editor, the Journal of Tropical Psychology
}

"This is a new day, fresh and untouched. What will we do with it?" -Morning welcome, Native American Church.

These days my own mornings do not begin untouched. They come with finger prints.

On our planet's north and south hemispheres outside what we think of as the tropical zone, half the year is growing warmer in an accelerating manner. The other half of the year is marked with extreme changes: sometimes even colder with heavier snowfall. Climate change has put more moisture in the air, leading to a redistribution of water on a global scale. Millennial floods in some places, severe drought in others. Insect species should thrive under these new conditions while other species, note the current devastation in our oceans, may find the new conditions more than they can survive.

The tropical zone is increasingly impacted year round. Without the great seasonal changes elsewhere, the heat raises ocean levels to the point where many communities are threatened. Floods and droughts are found here as well. Our tropical boundaries are expanding with each passing year. The increasing heat and humidity adds ever more countries to what may be considered a torrid or tropical zone, eventually one that may cover the planet with very few exceptions.

This makes our successful human adaptations to a more tropical world more essential to learn and share. We must do our part to track the psychology being done in these expanding territories of heat and light. Some of it may address behavioral strategies focused on coping or taking advantage of climate change challenges. Most will likely be the continuing progress of findings from psychologists in tropical regions that may be applied to enhancing human progress everywhere.

We usually think of our world as binomial. A forced choice between yes or no. Our computer code, so far, is binomial. Our statistics are largely based on this model of the world. We anticipate normal distributions. How often will the tossed coin land on one side or the other? Only two clear choices.

In life, my coin sometimes lands on its edge. Neither heads nor tails.

Therein lies our advantage. Our human family has survived this long by not accepting a choice between two bad alternatives. Instead, we can seek a better third. Psychologists often assist our clients to do this. We know how to generate fresh alternatives for coping with challenges. This is the basis for realistic hope.

Hope. Rollo May corrected me once when I said I was mostly an optimist (Morgan, 2012). Optimists outlive pessimists: they each fulfill their expectations (Morgan and Wilson, 2005). Rollo then said that optimism and pessimism are classic mistakes. He thought that the best we can do is be hopeful. But I am sure that we do not need passive hope. We can choose an active one, full of actions that can lead to hope fulfilled. From an existential point of view, we are fortunate to the extent that climate change is being caused by us, by our corporations, by our countries, or by us as individuals. If we are the cause of it, we have the best hope of creating changes to our advantage. Problems not caused by us are more difficult. If we are the problem, we are the solution.

Luckily we do not really live in a binomial world. We live in a world full of new possibilities. It is in fact a new day, fresh and untouched, except for the fingerprints that can turn out to be our own.

\section{References}

Morgan, R.F. (2012) Trauma psychology in context: international vignettes and applications. Albuquerque, N.M.: Sentinal/Morgan Foundation.

Morgan, R.F. \& Wilson, J. (2005) Growing Younger: How to Measure and Change Body Age. Albuquerque, NM: Morgan Foundation. 